\title{
Blind Test of Methods for Obtaining 2-D Near-Surface Seismic Velocity Models from First-Arrival Traveltimes
}

\author{
Colin A. Zelt ${ }^{1}$, Seth Haines ${ }^{2}$, Michael H. Powers ${ }^{3}$, Jacob Sheehan ${ }^{4}$, Siegfried Rohdewald ${ }^{5}$, Curtis Link ${ }^{6}$, \\ Koichi Hayashi ${ }^{7}$, Don Zhao ${ }^{8}$, Hua-wei Zhou ${ }^{9}$, Bethany L. Burton ${ }^{3}$, Uni K. Petersen ${ }^{10}$, Nedra D. Bonal ${ }^{11}$ \\ and William E. Doll ${ }^{12}$ \\ ${ }^{1}$ Department of Earth Science, Rice University, MS 126, 6100 Main St., Houston, TX 77005 \\ Email: czelt@rice.edu \\ ${ }^{2}$ United States Geological Survey, Central Energy Resources Science Center, MS 939, Denver Federal Center, Denver, \\ CO 80225 \\ Email: shaines@usgs.gov \\ ${ }^{3}$ United States Geological Survey, Crustal Geophysics \& Geochemistry Science Center, P.O. Box 25046, MS 964, \\ Denver, CO 80225 \\ Email:mhpowers@usgs.gov, blburton@usgs.gov \\ ${ }^{4}$ Zonge International, Inc., 7721 West $6^{\text {th }}$ Ave., Lakewood, CO 80214 \\ Email: jacob.sheehan@zonge.us \\ ${ }^{5}$ Intelligent Resources Inc., 757 West Hastings St., Vancouver, BC V6C 1A1, Canada \\ Email: info@rayfract.com \\ ${ }^{6}$ Department of Geophysical Engineering, Montana Tech, 1300 W. Park St., Butte, MT 59701 \\ Email: clink@mtech.edu \\ ${ }^{7}$ Geometrics, 2190 Fortune Dr., San Jose, CA 95131 \\ Email: khayashi@geometrics.com \\ ${ }^{8}$ Geogiga Technology Corp., 1600, 144-4Ave. SW, Calgary, AB T2P 3N4, Canada \\ Email: don@geogiga.com \\ ${ }^{9}$ Department of Earth \& Atmospheric Sciences, 312 Science \& Research 1, University of Houston, Houston, TX 77204 \\ Email: hzhou@uh.edu \\ ${ }^{10}$ Faroes Earth and Energy Directorate, Brekkutún 1, P.O. Box 3059, FO 110 Tórshavn, Faroe Islands \\ Email: up@jf.fo \\ ${ }^{11}$ Sandia National Laboratories, Geophysics \& Atmospheric Sciences, 1515 Eubank SE, Albuquerque, NM 87123 \\ Email: nbonal@sandia.gov \\ ${ }^{12}$ Battelle, 100A Donner Dr., Oak Ridge, TN 37830 \\ Email: dollw@battelle.org
}

\begin{abstract}
Seismic refraction methods are used in environmental and engineering studies to image the shallow subsurface. We present a blind test of inversion and tomographic refraction analysis methods using a synthetic first-arrival-time dataset that was made available to the community in 2010. The data are realistic in terms of the near-surface velocity model, shot-receiver geometry and the data's frequency and added noise. Fourteen estimated models were determined by ten participants using eight different inversion algorithms, with the true model unknown to the participants until it was revealed at a session at the 2011 SAGEEP meeting. The estimated models are generally consistent in terms of their large-scale features, demonstrating the robustness of refraction data inversion in general, and the eight inversion algorithms in particular. When compared to the true model, all of the estimated models contain a smooth expression of its two main features: a large offset in the bedrock and the top of a steeply dipping low-velocity fault zone. The estimated models do not contain a subtle low-velocity zone and other fine-scale features, in accord with conventional wisdom. Together, the results support confidence in the reliability and robustness of modern refraction inversion and tomographic methods.
\end{abstract}


Journal of Environmental and Engineering Geophysics

\section{Introduction}

Seismic refraction methods are commonly used to characterize the near-surface in environmental and engineering studies (e.g., Pelton, 2005). There are many different methods for obtaining a velocity model from seismic refraction first-arrival times, ranging from forward modeling to analytic and geometrical methods to inverse and tomographic methods (e.g., Palmer, 1980; Zelt and Smith, 1992; Sheehan et al., 2005; Ellefsen 2009). Near-surface P- and S-wave velocity models provide essential constraints in applications ranging from hydrologic characterization to site hazard evaluation (e.g., Deen and Gohl, 2002; Asten et al., 2005; Zelt et al., 2006; Powers et al., 2007; Martí et al., 2008; Yordkayhun et al., 2009), but often these models include little or no quantitative estimation of uncertainty, resolution or non-uniqueness. Furthermore, it is seldom possible to know the true velocity model that is being sought, thereby leaving open the question of how robust these methods are and how confident we can be in the results. Using surface wave data to obtain near-surface velocity models has recently become popular (e.g., Gabriels, et al., 1987; Park et al., 1999; Moro et al., 2007); however, the lateral resolution of these methods is inherently poor compared to body-wave methods.

We present the results of a blind test of 2-D firstarrival-time inversion and tomographic methods using a synthetic dataset derived from a feasible modern seismic refraction survey of a realistic near-surface target. The first two authors provided the community with a set of P-wave first-arrival times and the next 10 co-authors, ranging from seismic practitioners to algorithm developers, presented their estimated models at a session of the 2011 SAGEEP meeting before they knew the true model. This paper presents a comparison of the true model with 14 estimated models. The results provide an opportunity to "ground truth" 8 different algorithms using data from a known model, and thereby demonstrating some of their characteristic strengths and weaknesses. More importantly, the results as a whole show the level of model robustness that can be expected from first-arrival-time inversion/tomography of nearsurface data.

\section{True Model and Data}

The true velocity model (Fig. 1(a)) represents a geologic setting consisting of unconsolidated sediment overlying faulted bedrock. It includes several features that might be targeted in near-surface seismic surveys, including a thin low-velocity layer in the sediments $(5-\mathrm{m}$ deep between approximately $12.5 \mathrm{~m}$ and $112.5 \mathrm{~m}$ lateral position), a bedrock offset (centered at $95 \mathrm{~m}$ ), and a steeply-dipping low-velocity fault zone in the bedrock (centered at $185 \mathrm{~m}$ at $20-\mathrm{m}$ depth with $\sim 35^{\circ}$ dip). The model has zero surface topography. Velocities represent realistic P-wave velocities for unsaturated, unconsolidated sediments and clastic sedimentary or weathered metamorphic/igneous bedrock. The water table is not apparent, thus the geologic setting could be an arid region, or an area where the water table is deep. Although this model is not based on karst-type geology, the basic features are similar to what would be targeted in a survey of an epikarst system, i.e., an uneven bedrock surface with a high velocity contrast relative to overlying sediments. The model does not include other karst features such as blocks of limestone within the sediment and large voids in the bedrock.

The synthetic traveltimes correspond to P-wave first arrivals that were calculated assuming a $100 \mathrm{~Hz}$ wave using the method of Lomax (1994) adapted to a 2-D eikonal solver by Zelt et al. (2011). This method averages the velocity across roughly one wavelength centered on, and perpendicular to, the ray path (Fig. 2(a)). Uncorrelated Gaussianly-distributed noise with a mean of zero and a standard deviation of $1 \mathrm{~ms}$ was added to the synthetic data. The resulting set of traveltimes is referred to as the "true" data in this paper. There are 101 shots at locations from 0 to $300 \mathrm{~m}$, and 100 receivers at locations from 1.5 to $298.5 \mathrm{~m}$ with shot and receiver spacings of $3 \mathrm{~m}$. The total number of traveltimes is 10,100 (Fig. 2(b)).

\section{Modeling Approaches}

A brief description of the key modeling steps and assumptions used to derive the 14 estimated models (Fig. 3) are described in this section. All of the models are presented as submitted by the co-authors before the true model was known to them, except as described below in order to present them in a uniform format. A complete description of the eight algorithms used can be found in the cited references and web pages listed in Table 1. The root-mean-square (RMS) of the misfit between the data predicted by each estimated model and the true data is also listed in Table 1. Given that the true data contain uncorrelated, Gaussianly-distributed noise with a standard deviation of $1 \mathrm{~ms}$, the RMS misfits, ranging from 1.05 to $1.72 \mathrm{~ms}$, are reasonable (the RMS misfits are equal to the standard deviation of the residuals, assuming the mean is 0 ). Table 1 also lists four measures of comparison between each estimated model and the true model: the mean and standard deviation of the difference (estimated velocity minus true velocity) and the mean and standard deviation of 

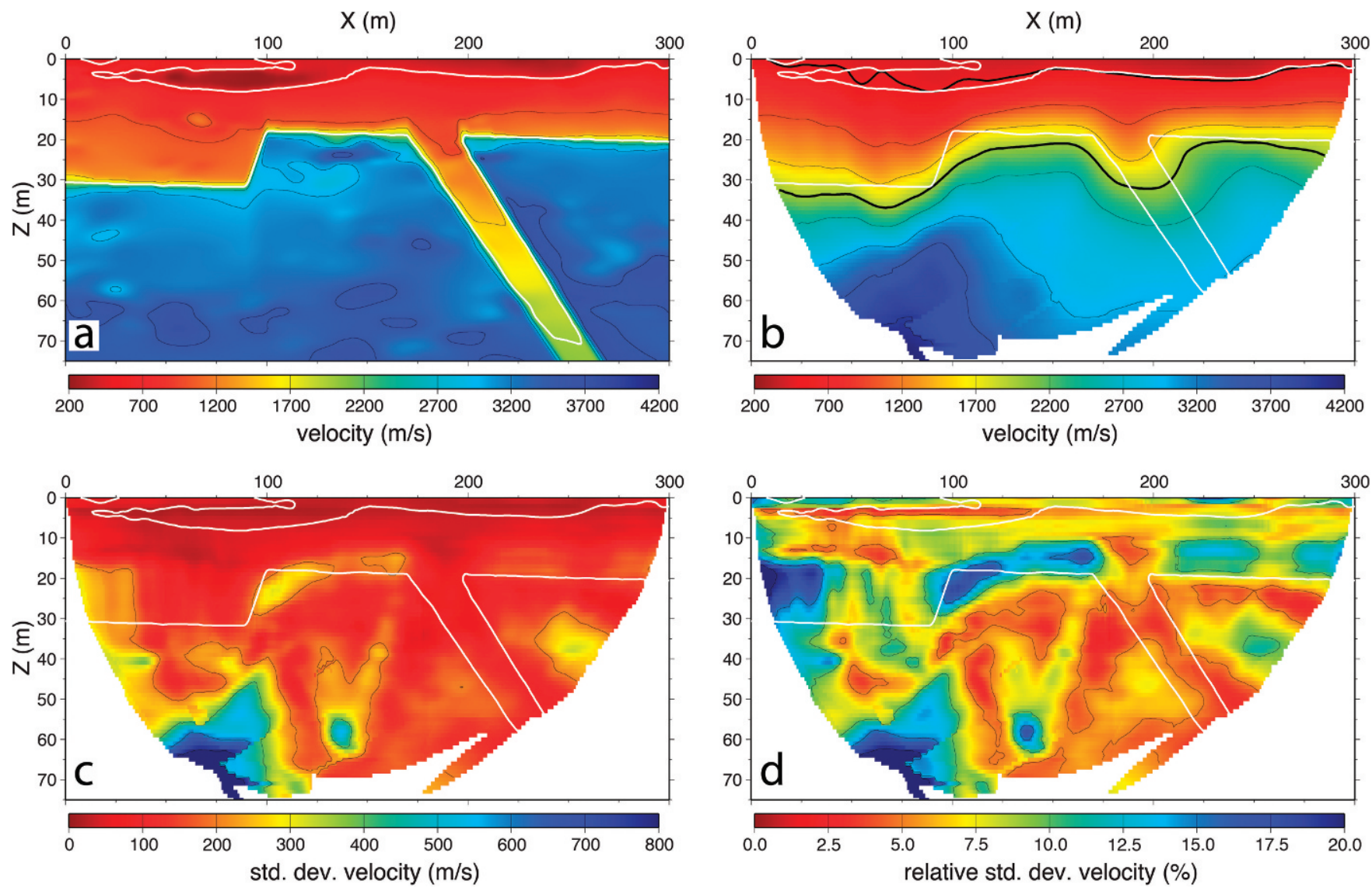

Figure 1. a) True model. White contours correspond to 500 and $2,000 \mathrm{~m} / \mathrm{s}$. b) Average of the estimated models. Black contours correspond to 500 and $2,000 \mathrm{~m} / \mathrm{s}$. White contours are from the true model for comparison. c) Standard deviation of the estimated models. d) Relative standard deviation of the estimated models.

the relative difference, where the relative difference in percentage equals:

$$
\Delta v_{\text {rel }}=\left[\frac{\left(v_{\text {estimated }}-v_{\text {true }}\right)}{v_{\text {true }}}\right] \times 100 .
$$

The mean and standard deviations in Table 1 are calculated over a portion of the model that is constrained in most of the estimated models as determined using the following procedure (this portion of the model is illustrated in Figs. 1(b-d)). The 14 final models were not all parameterized using the same horizontal and vertical node spacing. In addition, 8 of the 14 models are defined only at nodes where there is ray coverage. Those models that are not already parameterized on a grid of nodes positioned at $X=0$, 1,2 , etc. and $Z=0,1,2$, etc. meters, were re-sampled to conform to this consistent parameterization. There are three pairs of models ( 3 and 4, 5 and 6, and 7 and 8 ) that were derived by the same author using the same algorithm (Table 1). For the purpose of calculating the average of the estimated models and to define the constrained portion of the models, the two models in each of these three pairs were averaged to yield 3 models, defined only where there are nodes available in both of the models in the pair. The resulting set of 11 models was then averaged at each node that is constrained in at least 9 of the 11 models (Fig. 1(b)). To show the amount of variation across the models, the standard deviation of the difference and relative difference of these 11 models with respect to the average model was also calculated at the same set of nodes (Figs. 1(c-d)).

\section{Model 1}

This model was created using GeoCT-II version 3.1, a software product of GeoTomo, LLC, based on the algorithm described by Zhang and Toksoz (1998). A three-layer model with horizontal interfaces was used to start, determined by fitting an averaged traveltime curve. For all iterations, velocities were constrained to lie between 250 and $6,000 \mathrm{~m} / \mathrm{s}$. The first 30 iterations used minimal model smoothing. This output was used as input to an inversion of 20 more iterations with the smoothing increased by a factor of ten. An additional 
Journal of Environmental and Engineering Geophysics
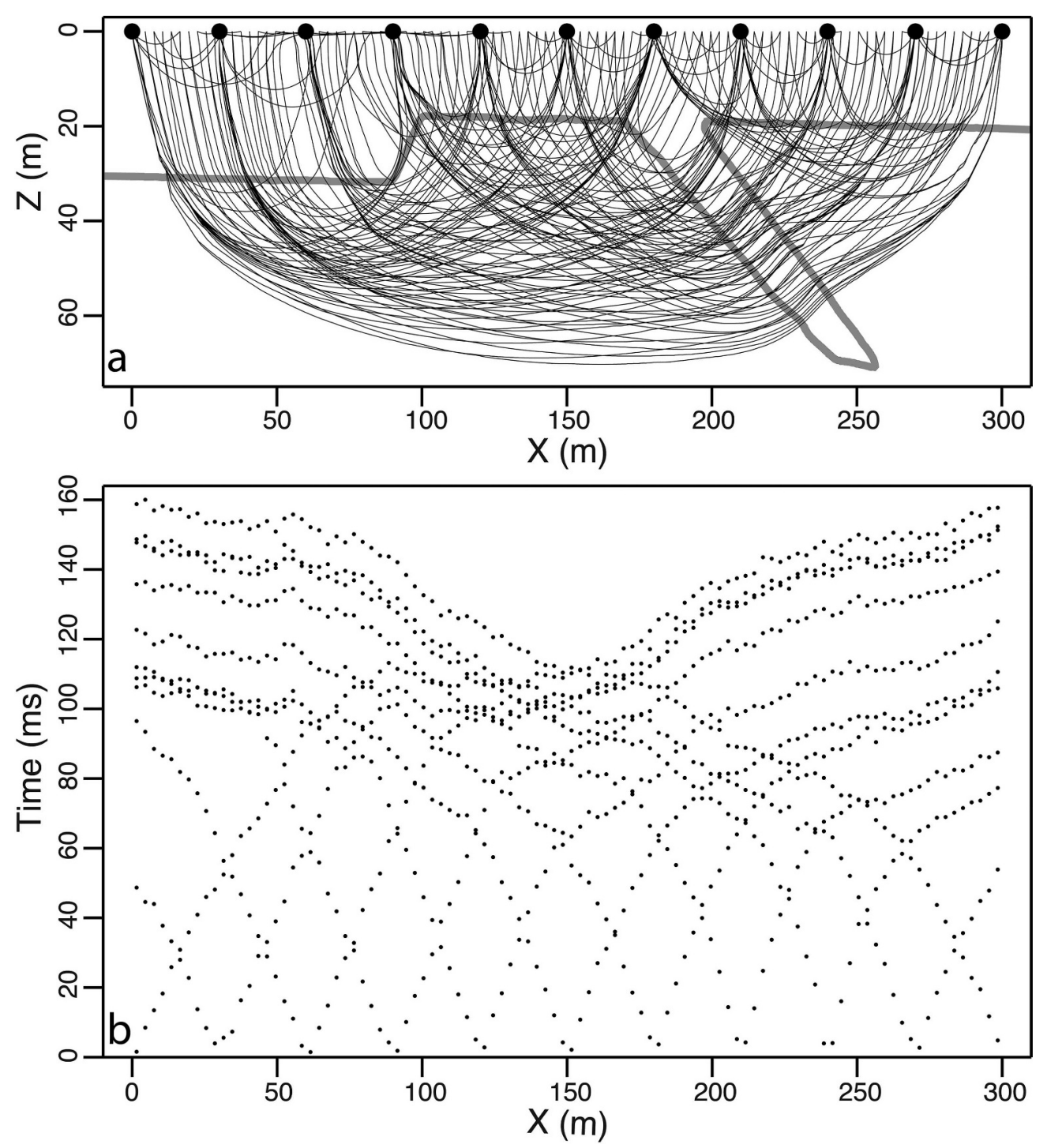

Figure 2. a) Ray paths through true model. For clarity, every $5^{\text {th }}$ path from every $10^{\text {th }}$ shot is shown. The $2,000 \mathrm{~m} / \mathrm{s}$ velocity contour is shown. b) Traveltimes from true model for every $10^{\text {th }}$ shot.

run of 20 more iterations with moderate smoothing resulted in the final model.

\section{Model 2}

This model was created using Rayfract ${ }^{\circledR}$ software version 3.16, the software package available through Intelligent Resources Inc. based on the wavepath eikonal traveltime (WET) inversion method of Schuster and Quintus-Bosz (1993). WET inversion uses the fresnel volume approach to model propagation of first-break energy in a physically meaningful way and the tomographic step assumes that the subsurface velocity varies smoothly. Sharp velocity contrasts are blurred and imaged with gradients (Sheehan et al., 2005). Fresnel volume tomography models finite-frequency effects such as diffraction, resulting in "fat rays." A minimum-structure starting model was obtained using the Delta-t-V method (Gebrande and Miller, 1985; Gibson et al., 1979) on common-midpoint gathers of the traveltime data with the subsequent 1-D velocity-depth profiles combined to create a smooth 2-D starting model. The inversion was constrained by a maximum velocity of $6,000 \mathrm{~m} / \mathrm{s}$ with the option for "minimal smoothing" after each of the 100 iterations.

\section{Models 3 and 4}

These models were created using a smooth inversion method with Rayfract ${ }^{\circledR}$ software version 3.18 from Intelligent Resources Inc. First, this approach automatically determines a 1-D initial model directly from the traveltimes by horizontally averaging the Delta-t-V method output (Sheehan et al., 2005). This 
Zelt et al.: Blind Test of First-Arrival Traveltime Inversion Methods
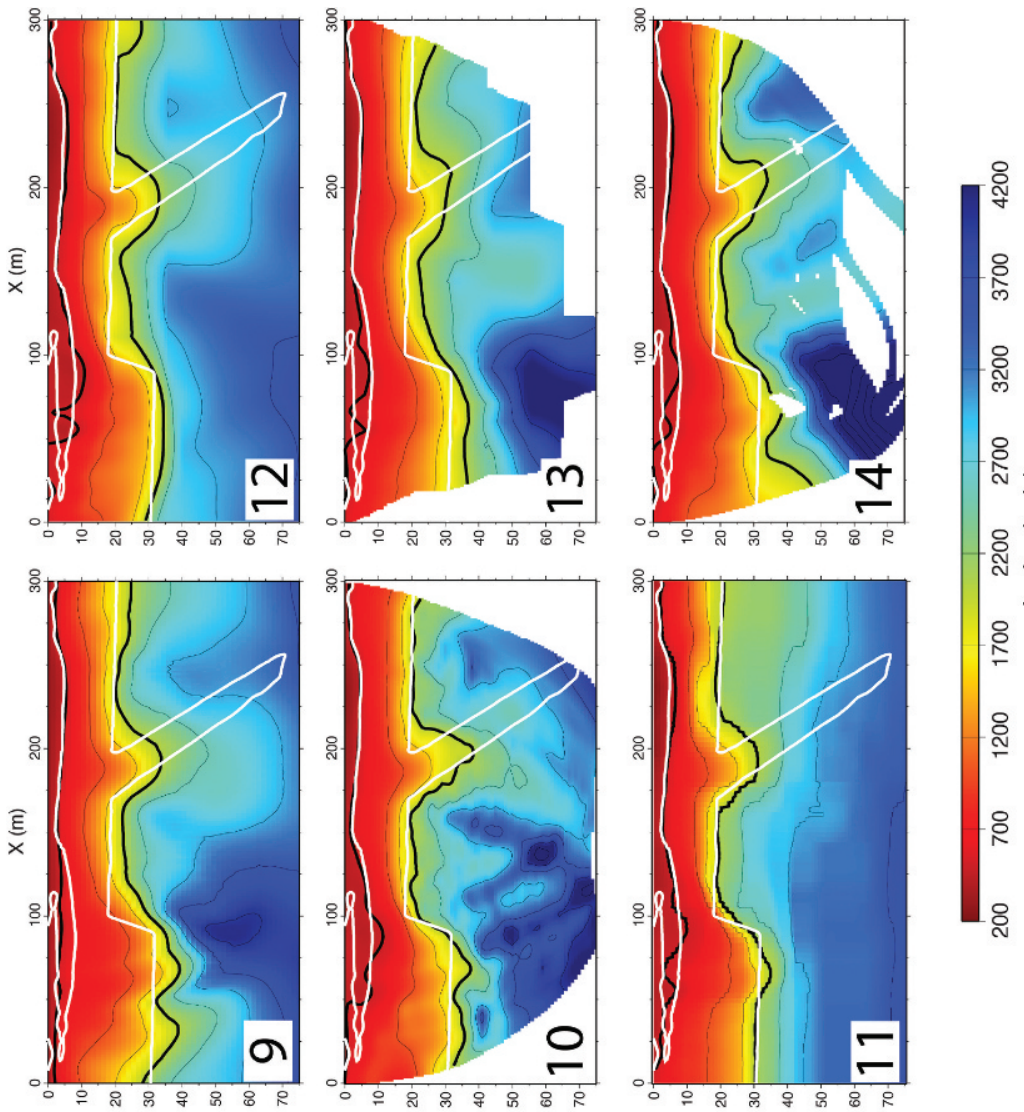

政
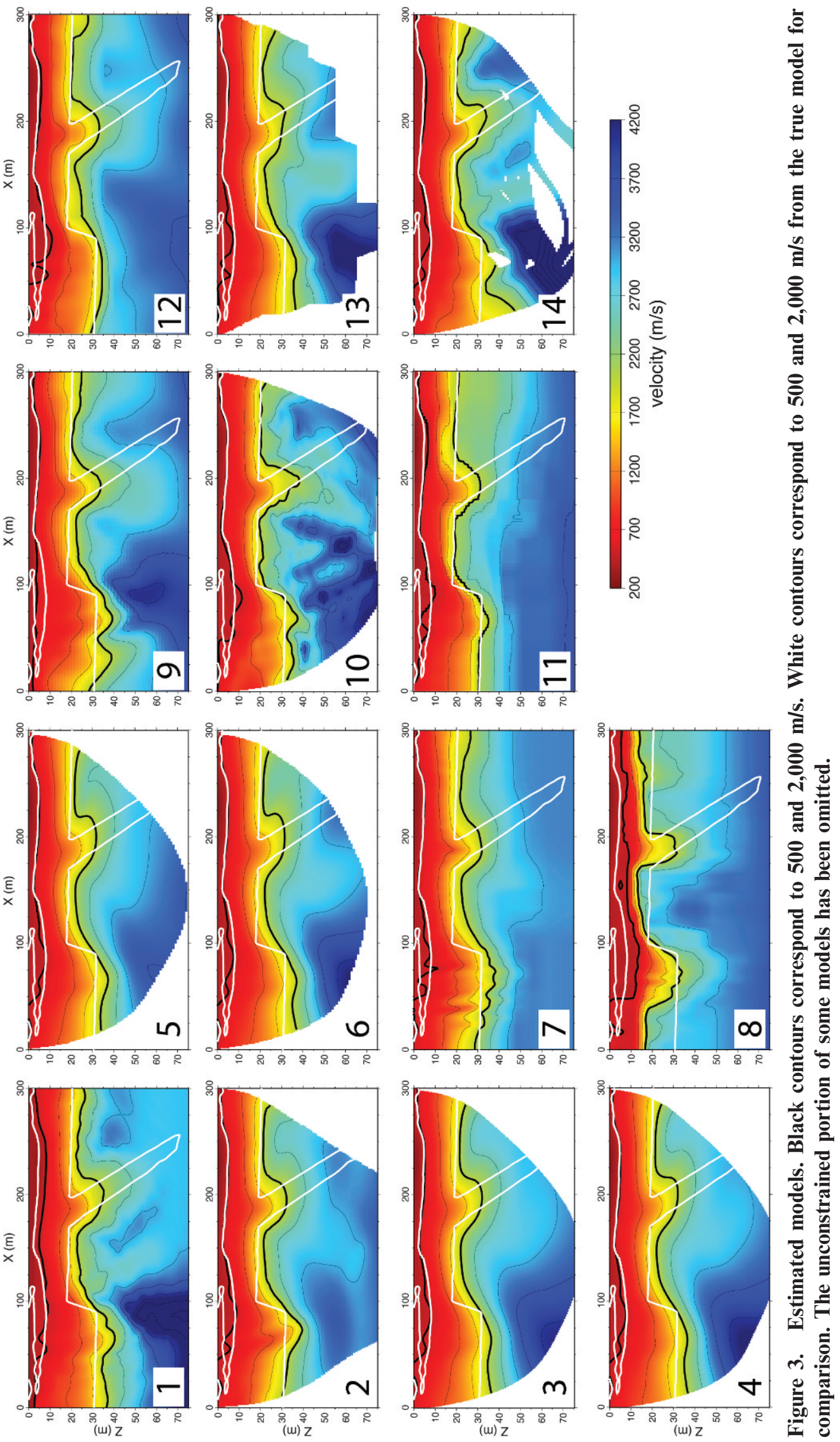
Table 1. Algorithms, fits and statistical comparisons with the true model for each estimated model.

\begin{tabular}{|c|c|c|c|c|c|c|c|}
\hline \multirow[b]{2}{*}{ Model } & \multirow[b]{2}{*}{ Algorithm } & \multirow[b]{2}{*}{ Reference } & \multirow[b]{2}{*}{$\mathrm{T}_{\mathrm{RMS}}(\mathrm{ms})$} & \multicolumn{2}{|c|}{ Difference } & \multicolumn{2}{|c|}{ Relative difference } \\
\hline & & & & $\operatorname{Mean}^{1}(\mathrm{~m} / \mathrm{s})$ & Std. dev. $(\mathrm{m} / \mathrm{s})$ & $\operatorname{Mean}^{1}(\%)$ & Std. dev. (\%) \\
\hline 1 & GeoTomo & $\begin{array}{l}\text { Zhang and } \\
\text { Toksoz (1998) }\end{array}$ & 1.3 & -237 & 564 & -9.3 & 24.0 \\
\hline 2 & Rayfract & rayfract.com & 1.08 & -208 & 466 & -3.2 & 23.4 \\
\hline 3 & Rayfract & rayfract.com & 1.17 & -174 & 491 & -2.7 & 23.3 \\
\hline 4 & Rayfract & rayfract.com & 1.18 & -172 & 506 & -2.7 & 23.6 \\
\hline 5 & Rayfract & rayfract.com & 1.18 & -189 & 470 & -2.5 & 23.6 \\
\hline 6 & Rayfract & rayfract.com & 1.17 & -185 & 517 & -2.4 & 24.9 \\
\hline 7 & Geometrics SeisImager/2-D & geometrics.com ${ }^{2}$ & 1.11 & -223 & 479 & -3.0 & 24.8 \\
\hline 8 & Geometrics SeisImager/2-D & geometrics.com ${ }^{2}$ & 1.40 & -16 & 524 & +7.1 & 37.9 \\
\hline 9 & Geogiga DW Tomo & geogiga.com ${ }^{3}$ & 1.72 & -166 & 522 & -1.5 & 26.4 \\
\hline 10 & Geogiga DW Tomo & geogiga.com ${ }^{3}$ & 1.13 & -111 & 469 & -0.6 & 22.1 \\
\hline 11 & $\begin{array}{l}\text { DLT (Deformable layer } \\
\text { tomography) }\end{array}$ & Zhou (2006) & 1.05 & -141 & 449 & -1.2 & 24.6 \\
\hline 12 & Phase Inversion & Ellefsen (2009) & 1.2 & -152 & 439 & -1.3 & 22.2 \\
\hline 13 & WARRP & $\begin{array}{l}\text { Ditmar et al. } \\
\quad(2009)\end{array}$ & 1.32 & -173 & 571 & -1.4 & 26.3 \\
\hline 14 & Tomog & $\begin{array}{l}\text { Preston et al. } \\
\quad(2007)\end{array}$ & 1.59 & -93 & 675 & +0.4 & 27.7 \\
\hline \multicolumn{8}{|c|}{$\begin{array}{l}{ }^{1} v_{\text {estimated }}-v_{\text {true }} \\
{ }^{2} \text { http://www.geometrics.com/geometr }\end{array}$} \\
\hline
\end{tabular}

1-D initial model is then iteratively refined with 2-D WET inversion (Schuster and Quintus-Bosz, 1993). For Model 3, a smooth Rayfract inversion was run with default parameters and 999 WET iterations. For Model 4, all velocities higher than $3,000 \mathrm{~m} / \mathrm{s}$ were reset to $3,000 \mathrm{~m} / \mathrm{s}$ in the initial Delta-t-V 1-D model, and WET was rerun using this modified starting model. The final models were obtained after the same number of WET iterations, using both the default and modified Delta-t-V initial models.

The two WET tomograms are very similar, despite the missing higher velocities in the modified Delta-t- $\mathrm{V}$ initial model. Also, these tomograms show minimum correlation with horizontal layering artifacts of the 1-D initial model, and agree with a wavefront refraction interpretation in which the first breaks were mapped interactively to assumed refractors and the layer-based wavefront refraction method of Ali Ak (1990) applied.

\section{Models 5 and 6}

These models were also generated using Rayfract ${ }^{\circledR}$ software that uses the WET tomography approach. Default parameter values were used with the following exceptions: the iteration count was increased to 200 and the wavepath width (percent of one period) was decreased to 4 percent. The effect of smoothing the noisy first arrival times and using a 1-D versus 2-D starting velocity model were investigated.

To obtain both final models the traveltimes were smoothed with a polynomial filter of degree two and a window size of 127 samples. The RMS difference for the filtered and raw times was $0.048 \mathrm{~ms}$. Model 5 used a 1-D initial velocity model and Model 6 used the 2-D Delta-t$\mathrm{V}$ initial model. These two models were compared with the models obtained using the same parameters and unfiltered (unsmoothed) traveltimes; the comparison reveals only small velocity differences in both cases, typically $10-20 \mathrm{~m} / \mathrm{s}$. The difference between the final models from the 1-D and 2-D starting models are only significant near the model edges, but are on the order of $5 \%$ or less elsewhere.

Models 7 and 8

These models were created using the SeisImager/2D software available from Geometrics. The intent was to show an example of model non-uniqueness associated with the initial model by using two different starting velocity models. For Model 7, the starting model was a simple 1-D velocity model in which velocity increases with depth. For Model 8, the starting model was a 2-D two-layer velocity model obtained through the delay time method; the velocities of the second layer were 


\section{Zelt et al.: Blind Test of First-Arrival Traveltime Inversion Methods}

manually determined from plots of the data using a reducing velocity. Although the two final models show some significant differences, their large-scale features are similar.

\section{Model 9}

This model was created using the software DW Tomo 6.0 developed by Geogiga Technology Corp. This method employs a gridded model, the graph method (also known as the shortest path method) to calculate traveltimes and raypaths, and a smoothing-regularized inverse approach to iteratively update the model. A velocity gradient model was used as the starting model with the surface velocity set to $400 \mathrm{~m} / \mathrm{s}$, the bottom velocity set to $5,000 \mathrm{~m} / \mathrm{s}$, and the maximum depth set to $100 \mathrm{~m}$. The model's horizontal and vertical grid spacing is $1.5 \mathrm{~m}$ and $1.0 \mathrm{~m}$. The smoothing lengths are $7.5 \mathrm{~m} \times 5 \mathrm{~m}$. The final model was obtained from the $10^{\text {th }}$ iteration.

$\underline{\text { Model } 10}$

This model was also created using the DW Tomo 6.0 software. For the model parameterization, a horizontal and vertical node spacing of 1 meter was used. The default smoothing parameters of $15 \mathrm{~m}$ horizontally and $3.75 \mathrm{~m}$ vertically resulted in a smooth model with an RMS misfit of $1.91 \mathrm{~ms}$. This is the model that would most likely have been chosen to submit to a client if this was real field data. However, to explore the range of models between those with very little detail and few artifacts and those with a high level of detail, but also some artifacts, the smoothing was decreased to $6 \mathrm{~m}$ horizontally and $2.5 \mathrm{~m}$ vertically. The resulting final model has more detail and an RMS misfit of $1.13 \mathrm{~ms}$, but it contains some inversion artifacts. However, the bedrock surface is imaged better using the lower smoothing parameters, suggesting that the lower smoothing could aid in interpretation, as long as the artifacts are recognized as such and not included in the interpretation.

\section{Model 11}

This model was created using the deformable layer tomography (DLT) method of Zhou (2006). The DLT method parameterizes the model with a number of thickness-varying layers, and each layer's velocity function can be constant, a gradient, or laterally varying. The method is able to invert for either the layer geometry, or layer velocity functions, or both simultaneously. A multi-scale scheme is employed to regularize the inversion for layer geometry and velocity functions. There is no smoothing of the model during or after the inversion process. However, prior information was incorporated in the form of a no-low-velocity-zone assumption such that the velocity is forced to increase with depth at each $\mathrm{X}$ position.
The DLT method was carried out in three steps. First, a long-wavelength model was built by inverting for the layer geometry of 12 constant-velocity layers; this 12-layer model reduced the RMS misfit to $1.99 \mathrm{~ms}$. Second, the model was divided into 34 layers and the inversion for layer geometry resulted in an RMS misfit of $1.17 \mathrm{~ms}$. Finally, both the layer geometries and velocities were inverted for, yielding an RMS misfit of $1.05 \mathrm{~ms}$. The non-low-velocity-zone assumption ensured a stable solution, although it precluded the ability to resolve low-velocity zones.

\section{Model 12}

This model was created using a wave-based, phaseinversion method that is the frequency-domain equivalent of traveltime inversion initially developed by Min and Shin (2006) for large-scale seismic studies. The observed traveltimes are transformed to their frequency-domain equivalents, which are the observed phases. The calculated phases are obtained from the solution of the scalar Helmholtz equation. The model is updated using a backpropagation method that is based on Rytov wavepaths. Ellefsen (2009) modified the phase inversion method for application to near-surface data, including the parameterization of the model, corrections to the observed phases, and selection of an appropriate complex frequency. The model for the modified inversion is isotropic and it is parameterized using the natural logarithm of the slowness.

A smooth starting model was generated using a separate time-domain method that provided an RMS misfit of less than $10 \mathrm{~ms}$. For the phase inversion, a complex frequency of $20+i 80 \mathrm{~Hz}$ was chosen that satisfies the criterion in Ellefsen (2009). Because the current implementation of phase inversion requires significant computer memory, only the traveltimes from every fourth shot were used, for a total of 26 shots, yielding a final RMS misfit of $1.2 \mathrm{~ms}$. A forward calculation of all 101 shots using the final model also yields an RMS misfit of $1.2 \mathrm{~ms}$, implying that the model structure estimated using 26 shots is sufficient to fit the data from all 101 shots.

\section{Model 13}

This model was created using the WARRP (Wide Aperture Reflection/Refraction Profiling) algorithm (Ditmar et al., 1999). Both interface geometries and the velocity distribution in layers are determined. The intensity of model smoothing is applied as a fractional change of velocities determined by the user. The inversion was done sequentially layer by layer, to a total of four layers, by first inverting to obtain a velocity profile and then establishing the position of the next interface by gather analyses. The model grid spacing was $10.2 \mathrm{~m}$ vertically and horizontally. Finally, ray density 
Journal of Environmental and Engineering Geophysics
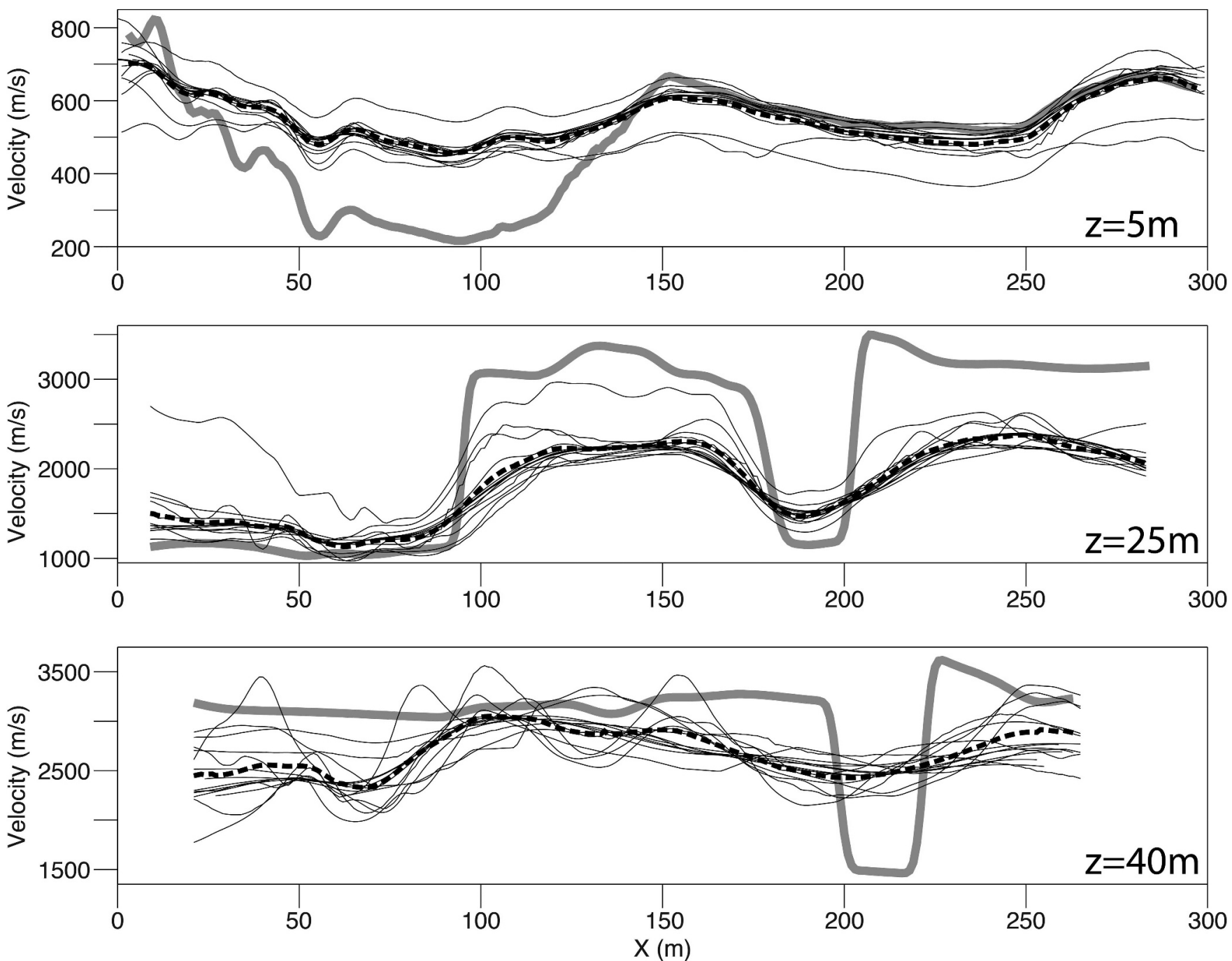

Figure 4. Comparison of horizontal slices through the true model (thick gray line), average estimated model (thick dashed line) and each estimated model at $\mathrm{Z}=5,25$ and $40 \mathrm{~m}$.

distribution analysis was used to exclude parts of the model with little ray coverage.

\section{Model 14}

This model was created using the tomographic program of Preston et al. (2007) in which an iterative inverse procedure is used to find incremental changes in model parameters to optimally fit travel-time residuals (observed minus calculated), subject to velocity structure smoothing constraints using a Laplacian operator that can accommodate different degrees of smoothing in the vertical and horizontal directions. Ray paths are calculated by following the finite-difference (eikonal) traveltime gradient from a receiver to the source. Model slowness perturbations are solved for by a conjugategradient least-squares approach.

A rough initial velocity model (two layers over a half space) was developed using an average of all shot records. Model grid node spacing is $1 \mathrm{~m}$. Model roughness, initially set low (very smooth), was allowed to increase with successive iterations until the traveltime residuals did not decrease sufficiently relative to model roughness increases.

\section{Results}

Figures 4 and 5 show horizontal and vertical profiles, respectfully, from the 14 estimated models, as well as the true model and the average of the estimated models. These profiles, along with Figs. 1(c-d), show that the variation between the models generally increases with depth. This illustrates the greater level of model uncertainty and non-uniqueness in the deeper parts of models derived from refraction data using first-arrival times caused by the decreasing number of rays and range of ray angles sampling the model as depth 

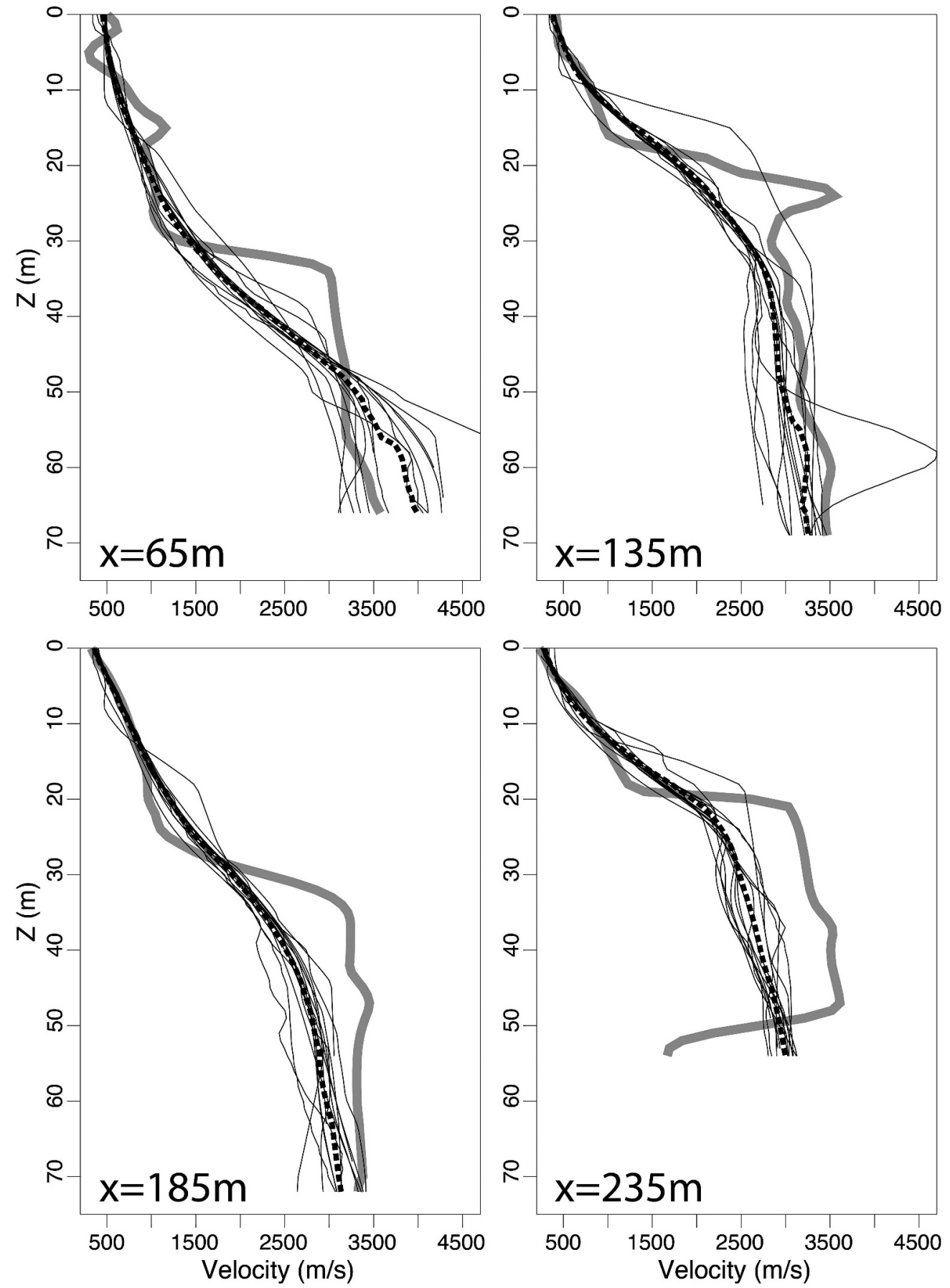

Figure 5. Comparison of vertical slices through the true model (thick gray line), average estimated model (thick dashed line) and each estimated model at $X=65,135,185$ and $235 \mathrm{~m}$.

increases. The majority of the constrained model region has a variation among the estimated models with a standard deviation of less than $200 \mathrm{~m} / \mathrm{s}$ (Fig. 1(c)) or less than $10 \%$ (Fig. 1(d)). Other than near the edges of the constrained model region, the location with the greatest variation among the estimated models is at the top of the basement between lateral positions 90 and $170 \mathrm{~m}$, i.e., between the basement offset and the dipping fault zone (Figs. 4 and 5). This may be because most of the modeling approaches seek a smooth model and have performed differently in how they handle this segment of the basement that is a sharp feature in the true model, both vertically and horizontally.

The RMS misfit between the true and predicted data for the 14 models varies from 1.05 to $1.72 \mathrm{~ms}$ (Table 1). One would expect that the models with the 
Journal of Environmental and Engineering Geophysics

lowest RMS misfits (models 11, 2 and 7) would contain the most structure and that the models with the highest RMS misfits (models 9, 14 and 8) would contain the least amount of structure. However, this trend is not observed, suggesting that the amount of structure in the estimated models is controlled by the particular algorithm used and assumptions made, rather than the fit between the true and predicted data. The mean of the difference between the estimated and true velocities shows that the estimated models are biased toward low velocities, averaging $160 \mathrm{~m} / \mathrm{s}$ lower than the true velocity (Table 1). The standard deviation of the difference between the estimated and true velocities is quite consistent and surprisingly high, averaging $\sim 500 \mathrm{~m} / \mathrm{s}$. The mean of the relative difference between the estimated and true velocities is generally quite small, averaging $\sim 1.7 \%$. Also, the standard deviation of the relative difference between the estimated and true velocities is quite consistent, averaging $\sim 25 \%$. The reason the mean is large by comparison to the relative mean is that the velocities in the model vary by a factor of about 15, and the mean is dominated by the differences in the high velocity regions. Overall, the two measures of velocity difference are surprisingly similar for all the estimated models, despite the fact that the models are quite different (Fig. 3), suggesting these differences are dependent on the model and the data, not the algorithm used or assumptions made.

The average estimated model includes a smooth approximation of the large-scale structure of the true model (Fig. 1), although the shallow low-velocity zone at $\sim 5$ - $\mathrm{m}$ depth between $\mathrm{X}=12.5$ and $125 \mathrm{~m}$ is absent in the average estimated model, and in all of the individual estimated models (Fig. 5). This confirms the longidentified inability of conventional first-arrival-time methods to image a low-velocity zone unless it is large in size and/or magnitude. The offset in the bedrock centered at $X=95 \mathrm{~m}$ is smoothly represented in the average model, and all of the estimated models, as is the top of the dipping low-velocity fault zone centered at $\mathrm{X}$ $=185 \mathrm{~m}$. The expression of the dipping fault zone is consistent, albeit very smooth, in the estimated models, reflected in the low relative standard deviation of the models of $\sim 5 \%$ at the fault location (Fig. 1(d)). The fault zone anomaly fades away near the base of ray coverage at about $50-\mathrm{m}$ depth in the average model. The average estimated model, and the majority of the individual estimated models, overestimate the basement velocity below $\sim 40-\mathrm{m}$ depth on the left side of the model. Exceptions to this are models 2, 5, 7, 8, 11 and 12. This is likely because of the reduced lateral resolution caused by predominantly sub-horizontal ray coverage at this depth (Fig. 2), and/or an overestimation of velocity in the starting models at this depth, and/or a velocity-depth tradeoff related to the failure to image the shallow low-velocity zone, the offset in the basement at $\mathrm{X}=95 \mathrm{~m}$, and the dipping low-velocity zone on the right side of the basement. A comparison between the white and black 2,000 m/s velocity contours in Fig. 3, a rough proxy for the bedrock contact in this case, shows that most of the estimated models predict this contour to be deeper than the true contour; exceptions are models 8,10 and 11 . This is likely because of the way in which a sharp boundary is represented in a smooth tomographic model.

\section{Discussion and Conclusions}

The model(s) derived using any particular algorithm in this paper cannot be expected to fully represent all the advantages and disadvantages of that algorithm. The final models are as much a consequence of the subjective modeling choices made by a particular author as they are a function of the software used. Therefore, the main contribution of this paper is in providing a sense of the range of models that can result from different people using different algorithms analyzing the same set of first-arrival traveltime data, as opposed to a determination of the best or worst algorithm.

Overall, the 14 models are consistent in terms of their large-scale features (Fig. 3) and they show the large-scale features of the true model, making the case that refraction inversion and tomography is robust. This is especially significant when considering that the eight algorithms used vary significantly in their model parameterization (i.e., fine grid versus layered), forward and inverse modeling approaches, and prior information (i.e., amount of model smoothing or lack there of). However, model differences only reflect the algorithms used and assumptions made, they do not reflect differences in first-arrival picking, which would occur with different people picking the same set of real data.

All methods used in this paper, except the multiscale approach of the DLT method (model 11), use some form of model smoothing constraint to seek a smooth model. This is a common methodological aspect of seismic tomography and it is intended to deal with model non-uniqueness and to keep the model smooth in accordance with the assumptions of ray theory. It is also used to honor Occam's principle, which states that the simplest, i.e., minimum-structure, solution is the best (Constable et al., 1987). However, enforcing model smoothness must be considered when interpreting a final model and assessing its geological reasonableness. For example, if a relatively sharp boundary is believed to exist, then its position and shape in a smooth model will be indicated by the velocity contour that corresponds to a value that is roughly midway between the velocities 


\section{Zelt et al.: Blind Test of First-Arrival Traveltime Inversion Methods}

above and below the actual boundary (Zelt et al., 2003). In the case of the 14 estimated models in this paper, all of them are smooth, but all of them contain an expression of two of the most prominent features in the true model, that is, the bedrock offset centered at $\mathrm{X}=95 \mathrm{~m}$, and the dipping low-velocity fault zone starting at $X=185 \mathrm{~m}$ at $20-\mathrm{m}$ depth. Furthermore, if these models were derived from real data, and if there were some prior knowledge of the study area suggesting that either of these features might be present somewhere in the subsurface, an interpretation of any of these models would accurately locate the lateral position of these two features. On the other hand, the depth of the bedrock surface is typically overestimated by a few meters $(\sim 10 \%$ of the depth) using the $2,000 \mathrm{~m} / \mathrm{s}$ contour as a proxy in the smooth models. Also, none of the estimated models contain an expression of the shallow low-velocity zone on the left side in the true model, presumably because it is relatively small in size and weak in magnitude (no more than $\sim 200 \mathrm{~m} / \mathrm{s}$ ).

The type of survey needed to acquire the true data-101 shots recorded by a static array of 100 geophones-is realistic for modern refraction surveys (e.g., Powers et al., 2007). The results of using the phase inversion method to derive model 12 suggest that as few as 26 shots could yield a sufficiently accurate model in terms of the large-scale features. This shows that the time, equipment and human resources needed to carry out a successful 2-D refraction survey are relatively modest compared to a typical seismic reflection survey. In addition, the seismograms from a refraction survey can be exploited further than just using the first-arrival times. For example, some modeling algorithms allow later refracted and reflected arrivals to be used to provide additional model constraint, in particular, on the geometry of layer boundaries, such as the bedrock surface in this study. Finally, refraction data can be amenable to conventional multi-channel reflection processing to yield a low-fold stack, as well as 2-D full waveform inversion (e.g., Gao et al., 2007; Smithyman et al., 2009).

\section{Acknowledgements}

Karl J. Ellefsen (U.S. Geological Survey) and Leiph A. Preston (Sandia National Laboratories) helped to develop models 12 and 14, respectively. The review of the manuscript by Karl J. Ellefsen is gratefully acknowledged. CZ acknowledges support from DOE grant DE-FG02-03ER63662. Sandia National Laboratories is a multi-program laboratory operated by Sandia Corporation, a wholly owned subsidiary of Lockheed Martin company, for the U.S. Department of Energy's National Nuclear Security Administration under contract DEAC04-94AL85000. References to any specific commercial product, process, or service by trade name, trademark, manufacturer, or otherwise does not constitute or imply its endorsement, recommendation, or favoring by the United States Government or any agency thereof.

\section{References}

Ali Ak, M., 1990, An analytical raypath approach to the refraction wavefront method: Geophysical Prospecting, 38, 971-982.

Asten, M.W., Stephenson, W.R., and Davenport, P.N., 2005, Shear-wave velocity profile for Holocene sediments measured from microtremor array studies, SCPT, and seismic refraction: Journal of Environmental and Engineering Geophysics, 10, 235-242.

Constable, S.C., Parker, R.L., and Constable, C.G., 1987, Occam's inversion: a practical algorithm for generating smooth models from electromagnetic sounding data: Geophysics, 52, 289-300.

Deen, T., and Gohl, K., 2002, 3-D tomographic seismic inversion of a paleochannel system in central New South Wales, Australia: Geophysics, 67(5) 1364-1371.

Ditmar, P., Penopp, J., Kasig, R., and Makris, J., 1999, Interpretation of shallow refraction seismic data by reflection/refraction tomography: Geophysical Prospecting, 47, 871-901.

Ellefsen, K.J., 2009, A comparison of phase inversion and traveltime tomography for processing near-surface refraction traveltimes: Geophysics, 74(6) WCB11-WCB24.

Gabriels, P., Snieder, R., and Nolet, G., 1987, In situ measurements of shear-wave velocity in sediments with higher-mode Rayleigh waves: Geophysical Prospecting, 35, 187-196.

Gao, F., Levander, A., Pratt, R.G., Zelt, C.A., and Fradelizio, G.-L., 2007, Waveform tomography at a ground water contamination site: Surface reflection data: Geophysics, 72, G45-G55.

Gebrande, H., and Miller, H., 1985, Refraktionsseismik (in German) in Angewandte Geowissenschaften II, Bender, F. (ed.), Ferdinand Enke, Stuttgart, 226-260.

Gibson, B.S., Odegard, M.E., and Sutton, G.H., 1979, Nonlinear least-squares inversion of traveltime data for a linear velocity-depth relationship: Geophysics, 44, 185-194.

Lomax, A., 1994, The wavelength-smoothing method for approximating broad-band wave propagation through complicated velocity structures: Geophysical Journal International, 117, 313-334.

Martí, D., Carbonell, R., Flecha, I., Palomeras, I., Font-Capó, J., Vázquez-Suñé, E., and Pérez-Estaún, A., 2008, Highresolution seismic characterization in an urban area: Subway tunnel construction in Barcelona, Spain: Geophysics, 73(2) B41-B50.

Min, D.J., and Shin, C., 2006, Refraction tomography using a waveform-inversion back-propagation technique: Geophysics, 71(3) R21-R30.

Moro, G.D., Pipan, M., and Gabrielli, P., 2007, Rayleigh wave dispersion curve inversion via genetic algorithms and 
Journal of Environmental and Engineering Geophysics

marginal posterior probability density estimation: Journal of Applied Geophysics, 61, 39-55.

Palmer, D., 1980. The generalized reciprocal method of seismic refraction interpretation, Society of Exploration Geophysics, Tulsa, OK, 104 pp.

Park, C.B., Miller, R.D., and Xia, J., 1999, Multi-channel analysis of surface waves: Geophysics, 64, 800-808.

Pelton, J.R., 2005, Near-surface seismology: Surface-based methods in Near-Surface Geophysics, Butler, D. (ed.), Society of Exploration Geophysics, Tulsa, OK, 219-263.

Powers, M.H., Haines, S., and Burton, B.L., 2007, Compressional and shear wave seismic refraction tomography at Success Dam, Porterville, California: in Proceedings of the Symposium on the Application of Geophysics to Engineering and Environmental Problems, 20, 31-40.

Preston, L., Smith, K., and von Seggern, D., 2007, P wave velocity structure in the Yucca Mountain, Nevada region: Journal of Geophysical Research, 112, B11305, doi: 10.1029/2007JB005005.

Schuster, G.T., and Quintus-Bosz, A., 1993, Wavepath eikonal traveltime inversion-Theory: Geophysics, 58(9) 1314 1323.

Sheehan, J.R., Doll, W.E., and Mandell, W., 2005, An evaluation of methods and available software for seismic refraction tomography analysis: Journal of Environmental and Engineering Geophysics, 10(1) 21-34.
Smithyman, B., Pratt, R.G., Hayles, J., and Wittebolle, R., 2009, Detecting near-surface objects with seismic waveform tomography: Geophysics, 74, WCC119-WCC127.

Yordkayhun, S., Tryggvason, A., Norden, B., Juhlin, C., and Bergman, B., 2009, 3D seismic traveltime tomography imaging of the shallow subsurface at the CO2SINK project site, Ketzin, Germany: Geophysics, 74(1) G1-G15.

Zelt, C.A., Azaria, A., and Levander, A., 2006, 3D seismic refraction traveltime tomography at a groundwater contamination site: Geophysics, 71(5) H67-H78.

Zelt, C.A., Liu, H., and Chen, J., 2011. Frequency-dependent traveltime tomography for near-surface seismic data: Sensitivity kernels and synthetic and real data examples, Abstract NS41A-05, Fall Meeting, AGU, San Francisco, CA.

Zelt, C.A., Sain, K., Naumenko, J.V., and Sawyer, D.S., 2003, Assessment of crustal velocity models using seismic refraction and reflection tomography: Geophysical Journal International, 153, 609-626.

Zelt, C.A., and Smith, R.B., 1992, Seismic traveltime inversion for 2-D crustal velocity structure: Geophysical Journal International, 108, 16-34.

Zhang, J., and Toksoz M, N., 1998, Nonlinear refraction traveltime tomography: Geophysics, 63, 1726-1737.

Zhou, H., 2006, Multiscale deformable-layer tomography: Geophysics, 71, R11-R19. 